Marcel Bazin, Stéphane de Tapia, La Turquie : géographie d'une puissance émergente

\title{
Elvan Arik
}

\section{(2) OpenEdition}

\section{Journals}

Édition électronique

URL : http://journals.openedition.org/geocarrefour/8791

ISSN : 1960-601X

\section{Éditeur}

Association des amis de la Revue de géographie de Lyon

Édition imprimée

Date de publication : 25 décembre 2014

Pagination : 210

ISSN : 1627-4873

Ce document vous est offert par Aix-Marseille Université (AMU)

\section{Aix Marseille université}

Référence électronique

Elvan Arik, «Marcel Bazin, Stéphane de Tapia, La Turquie : géographie d'une puissance émergente», Géocarrefour [En ligne], vol. 89/3 | 2014, mis en ligne le, consulté le 21 juin 2019. URL : http:// journals.openedition.org/geocarrefour/8791

Ce document a été généré automatiquement le 21 juin 2019.

(c) Géocarrefour 


\title{
Marcel Bazin, Stéphane de Tapia, La Turquie : géographie d'une puissance émergente
}

\author{
Elvan Arik
}

\section{RÉFÉRENCE}

BAZIN M., TAPIA S. DE, 2012, La Turquie : géographie d'une puissance émergente, Paris, Armand Colin, $336 \mathrm{p}$.

1 Chaussée de ses bottes de sept lieues, stimulée par une vitalité économique et démographique toujours forte, La Turquie en marche de Jean-François Pérouse (Pérouse, 2004) aurait-elle gravi une nouvelle étape dans sa course développementaliste en rejoignant la catégorie des puissances émergentes? Malgré un titre affirmatif qui ne semble à première vue laisser guère de place au doute, La Turquie: géographie d'une puissance émergente, Marcel Bazin et Stéphane de Tapia se livrent tout au long de leur ouvrage à une analyse géographique pour interroger cette notion d'émergence, ou du moins pour mieux saisir toute la complexité des dynamiques socio-spatiales, à l'œuvre sur le territoire turc, que cette notion entend décrire.

2 A la lecture de ce travail présenté sous la forme d'une monographie dense et richement documentée, d'aucuns seront impressionnés par l'accumulation de connaissances remarquablement synthétisées et structurées en six chapitres. Sont ainsi abordés des sujets aussi vastes que l'histoire de la formation du territoire et de l'Etat turc (chapitre 1), l'organisation et la restructuration de l'agriculture selon la variété des milieux naturels (chapitre 2), l'inégal développement socio-économique et industriel entre l'Est et l'Ouest du territoire (chapitre 3) accentué, d'une part par la concentration des infrastructures de transports et touristiques (chapitre 4) et, de l'autre par un réseau urbain, certes relativement homogène spatialement, mais marqué du poids de la métropolisation de certains pôles urbains situés majoritairement à l'Ouest (chapitre 5). 
3 Le chapitre 6 intitulé «Une ouverture vers des horizons variés » résume à lui seul l'ambition poursuivie par les auteurs de l'ouvrage, à savoir complexifier le positionnement politique, social, économique et culturel d'une Turquie qui fascine mais qui reste néanmoins méconnue. La Turquie qu'ils décrivent de l'intérieur, grâce à une pratique de longue date et régulière du terrain, les contraint inévitablement à se départir des traditionnels arguments géographiques qui n'ont servi qu'à stigmatiser arbitrairement le caractère non-européen du pays. Cette puissance émergente mythifiée (représentation orientalisée du Turc selon les époques, question de la modernité dans un pays musulman et laïque, épisodiquement mais régulièrement jugé autoritariste au gré de l'histoire, réduction de la Turquie à son caractère méditerranéen...), située aux portes de l'Europe, est ainsi repositionnée dans un cadre géographique de référence plus large intégrant notamment ce que les auteurs appellent la nouvelle "aire turque " formée à partir des récentes mobilités individuelles internes et externes au territoire turc. Les auteurs balaient ainsi l'image d'Epinal selon laquelle la Turquie représenterait un réservoir d'émigrants prêts à affluer vers les pays européens, puisque l'on apprend que les destinations des nouvelles migrations sont avant tout multiples, pour ne pas dire mondialisées (Moyen-Orient, Afrique du Nord, pays de l'ex-bloc soviétique y compris la Russie, Amérique du Nord et Australie). De plus, la Turquie est désormais redevenue un pays d'immigration, "un pays d'accueil de cadres de multinationales, de migrants en transit, de travailleurs clandestins peu qualifiés, de réfugiés irakiens, iraniens, afghans» (p.274). Cette recomposition du champ migratoire turc peut être considérée comme, à la fois, cause et conséquence de l'émergence politico-économique du pays. Cause depuis que la politique économique d'inspiration libérale des années 1980, exclusivement tournée vers les exportations de biens et de services, a permis à la Turquie d'atteindre le $15^{\mathrm{e}}$ rang des puissances mondiales en termes de PIB ; mais aussi conséquence de la nouvelle politique étrangère du gouvernement AKP, cherchant notamment à affirmer progressivement la Turquie comme interlocuteur privilégié sur la scène régionale, en ranimant notamment les liens culturels et religieux qui unissent les pays musulmans, et comme acteur majeur de la scène économique internationale.

4 On l'aura compris, loin des clichés, cet ouvrage propose une étude accessible et stimulante de l'émergence de la Turquie analysée dans sa profondeur historique et dans son actualité politique et socio-économique tout en considérant la dimension spatiale de ces dynamiques comme centrale. Bien que l'indéniable succès économique du pays soit synonyme d'avancées sociales, Marcel Bazin et Stéphane de Tapia montrent que le phénomène d'émergence est bien plus le fait de certains territoires (Houssay-Holzschuch \& Fleury, 2012) - en schématisant, cela concerne les plus grandes villes dont particulièrement Istanbul, et l'ensemble de la façade maritime de l'Ouest turc - que du pays tout entier. Le seul regret concerne paradoxalement, de la part de géographes, la lecture malaisée des nombreuses cartes produites, trop réduites au regard de la richesse des informations censées être représentées et visuellement uniformisées par la seule utilisation du noir et blanc. Cette mise en page, ayant sans doute subi les contraintes du format d'édition, nous incite à penser qu'un projet d'atlas thématique sur la Turquie viendrait utilement compléter les propos des deux auteurs. Marcel Bazin et Stéphane de Tapia réussissent au final à illustrer de manière fine et intelligente les contrastes et les tensions d'une société en mutation, bousculée par une entrée fracassante dans la «modernité ». 


\section{BIBLIOGRAPHIE}

HOUSSAY-HOLZSCHUCH M. \& FLEURY A., 2012, Pour une géographie sociale des pays émergents, EchoGéo, (numéro 21). http://echogeo.revues.org/13167

PÉROUSE J.-F., 2004, La Turquie en marche: les grandes mutations depuis 1980, Paris, Éditions de La Martinière. 